\title{
Water treatment sludge for removal of heavy metals from electroplating wastewater
}

\author{
Anujkumar Ghorpade, M. Mansoor Ahammed ${ }^{\dagger}$ \\ Civil Engineering Department, S V National Institute of Technology, Surat-395007, India
}

\begin{abstract}
Suitability of aluminium-based water treatment sludge (WTS), a waste product from water treatment facilities, was assessed for removal of heavy metals from an electroplating wastewater which had high concentrations of copper and chromium along with other heavy metals. Batch tests with simulated wastewater in single- and multi-metal solutions indicated the influence of initial $\mathrm{pH}$ and WTS dose on removal of six metals namely $\mathrm{Cu}(\mathrm{II}), \mathrm{Co}(\mathrm{II}), \mathrm{Cr}(\mathrm{VI}), \mathrm{Hg}(\mathrm{II}), \mathrm{Pb}(\mathrm{II})$ and $\mathrm{Zn}$ (II). In general, removal of cationic metals such as $\mathrm{Pb}(\mathrm{II}), \mathrm{Cu}(\mathrm{II})$ and $\mathrm{Zn}(\mathrm{II})$ increased with increase in $\mathrm{pH}$ while that of anionic $\mathrm{Cr}(\mathrm{VI})$ showed a reduction with increased $\mathrm{pH}$ values. Tests with multi-metal solution showed that the influence of competition was more pronounced at lower WTS dosages. Column test with diluted (100 times) real electroplating wastewater showed complete removal of copper up to 100 bed volumes while chromium removal ranged between 78-92\%. Other metals which were present in lower concentrations were also effectively removed. Mass balance for copper and chromium showed that the WTS media had Cu(II) and $\mathrm{Cr}(\mathrm{VI})$ sorption capacities of about 1.7 and $3.5 \mathrm{mg} / \mathrm{g}$ of dried sludge, respectively. The study thus indicates that WTS has the potential to be used as a filtration/adsorption medium for removal of metals from metal-bearing wastewaters.
\end{abstract}

Keywords: Electroplating wastewater, Heavy metals, Sludge reuse, Water treatment sludge

\section{Introduction}

Wastewater from several industries such as electroplating, tannery, mining and steel contains elevated levels of heavy metals including chromium, cobalt, copper, nickel, zinc, mercury and lead. If the wastewaters were discharged directly into natural waters, it will constitute a great risk for the aquatic ecosystem, while the direct discharge into the sewerage system may negatively affect the subsequent biological wastewater treatment [1]. Additionally, increasing environmental awareness coupled with more stringent regulations has triggered various industries to challenge themselves in seeking appropriate wastewater treatment technologies [2]. Thus these toxic metals must be effectively treated/removed from the wastewaters. Many methods that are being used to remove heavy metal ions include chemical coagulation, ion-exchange, oxidation, adsorption, membrane filtration, and electrochemical treatment technologies. However, most of these techniques have drawbacks such as inadequate removal efficiency, production of large amounts of sludge, and need for high capital and running costs and high technology [3, 4]. Thus these methods are not viable for small industries in developing countries. Adsorption process involving the use of solid adsorbents has been widely studied for heavy metal removal. While activated carbon is the most commonly used adsorbent, efforts have been made to use low-cost sorbents for heavy metal removal $[5,6]$. Adsorptive treatment of heavy metals using non-conventional adsorbents such as agricultural and industrial solid wastes have been reported [6].

Large quantities of water treatment sludge (WTS) are produced globally as a by-product of coagulation and flocculation process while removing suspended and colloidal impurities from raw water [7]. Aluminium or iron salts are commonly used as coagulants and the resulting Fe-WTS or Al-WTS are primarily composed of amorphous iron or aluminium hydroxides respectively. They also contain inorganic and humic substances removed from the raw water and traces of coagulating agents used in the water treatment process [8]. At present these residuals are disposed (a) to sanitary sewers, (b) into a receiving stream and (c) by land application, assuming that these residuals do not possess any toxic characteristics [9-13]. Adverse impacts of WTS disposal on water bodies have been studied, and acute toxicity towards various aquatic life has been reported [14]. This has initiated greater interest in
This is an Open Access article distributed under the terms of the Creative Commons Attribution Non-Commercial License (http://creativecommons.org/licenses/by-nc/3.0/) which permits unrestricted non-commercial use, distribution, and reproduction in any medium, provided the original work is properly cited.
Received May 18, 2017 Accepted August 30, 2017

${ }^{\dagger}$ Corresponding author

Email: mansoorahammed@gmail.com

Tel: +91-261-2201827 Fax: +91-261-2228394

Copyright (C) 2018 Korean Society of Environmental Engineers 
the proper management of these residuals in an environmentally acceptable and sustainable manner. Recently, a number of studies have been reported in the literature on the reuse of WTS for different applications including its use in water and wastewater treatment $[15,16]$.

Because of their amorphous nature [16] and large surface area, water treatment sludge has been used as sorbent for removing different contaminants [10]. Wet/dry sludge has been used as a coagulant to remove different contaminants in water and wastewater. Recently, efforts have been made to assess the suitability of WTS for removing heavy metals [17-25]. These studies have shown that WTS is a cost-effective sorbent that can reduce the concentration of toxic heavy metals in aqueous solutions. Since heavy metals are a major environmental problem, the use of water treatment sludge for the removal of metals can be identified as a sustainable management technique.

Most of these studies with WTS reported in the literature, however, were performed under controlled conditions using synthetic single heavy metal solutions [18, 24]. Since real electroplating wastewater generally contains a number of different heavy metals, it is necessary to evaluate the potential of WTS with multi-metal solutions. The purpose of the present study was to investigate the potential of aluminium-based WTS to remove heavy metals from a real electroplating wastewater which had high concentration of chromium and copper along with other metals. Batch tests were conducted using simulated wastewater in single metal and multi-metal solutions. Long-duration column tests were conducted using a real electroplating wastewater.

\section{Materials and Methods}

\subsection{Water Treatment Sludge}

WTS was collected from the Bhandup water treatment plant, Mumbai, India which has a treatment capacity of 1,910 million litre per day. The processes used in this plant include sedimentation, coagulation, filtration and disinfection. Polyaluminium chloride (PACl) is used as the coagulant in this plant. Freshly generated aluminium-WTS in the wet form was collected from the plant. All the tests were conducted using a single batch of WTS collected on a particular day. The sludge had high solids content of $70 \%$. The sludge was oven-dried at $105^{\circ} \mathrm{C}$ for $48 \mathrm{~h}$. The dried sludge was crushed and sieved through $150 \mu \mathrm{m}$ sieve, and the portion retained on the sieve was used in the study.

Concentration of different elements in the sludge was estimated after acid digestion as per USEPA Method 3050B [26]. For this, $2.5 \mathrm{~g}$ of dried sludge was digested for two hours at $140^{\circ} \mathrm{C}$ with $4 \mathrm{~mL}$ of concentrated nitric acid and $12 \mathrm{~mL}$ of concentrated hydrochloric acid. After cooling, $50 \mathrm{~mL}$ of distilled water was added and mixed thoroughly. The supernatant was separated by centrifugation and was analysed for different metals. The elemental content and some key characteristics of the WTS sample are shown in Table 1. High concentrations of $\mathrm{Al}$ and Fe were present. Though PACl-based sludge was used in the present study, high Fe content found in the digested WTR solution could be due to the leaching of iron from the suspended solids present in the raw water and also due to the leaching of iron removed from the raw water during the coagulation process. Relatively high contents of $\mathrm{Ca}, \mathrm{Mg}$ and

Table 1. Characteristics of the Water Treatment Sludge

\begin{tabular}{lcc}
\hline \multicolumn{1}{c}{ Parameter } & Value & Unit \\
\hline $\mathrm{pH}$ & 7.29 & \\
Moisture content & 30 & \% of sludge \\
Total solids & 70 & \% of sludge \\
$\mathrm{Al}$ & 135.51 & $\mathrm{mg} / \mathrm{g}$ dry sludge \\
$\mathrm{Fe}$ & 89.82 & $\mathrm{mg} / \mathrm{g}$ dry sludge \\
$\mathrm{Ca}$ & 19.40 & $\mathrm{mg} / \mathrm{g}$ dry sludge \\
$\mathrm{Mg}$ & 12.28 & $\mathrm{mg} / \mathrm{g}$ dry sludge \\
$\mathrm{K}$ & 5.02 & $\mathrm{mg} / \mathrm{g}$ dry sludge \\
$\mathrm{Mn}$ & 2.2 & $\mathrm{mg} / \mathrm{g}$ dry sludge \\
$\mathrm{Na}$ & 1.3 & $\mathrm{mg} / \mathrm{g}$ dry sludge \\
$\mathrm{Si}$ & 123.5 & $\mathrm{mg} / \mathrm{g}$ dry sludge \\
$\mathrm{P}$ & 4.3 & $\mathrm{mg} / \mathrm{g}$ dry sludge \\
\hline
\end{tabular}
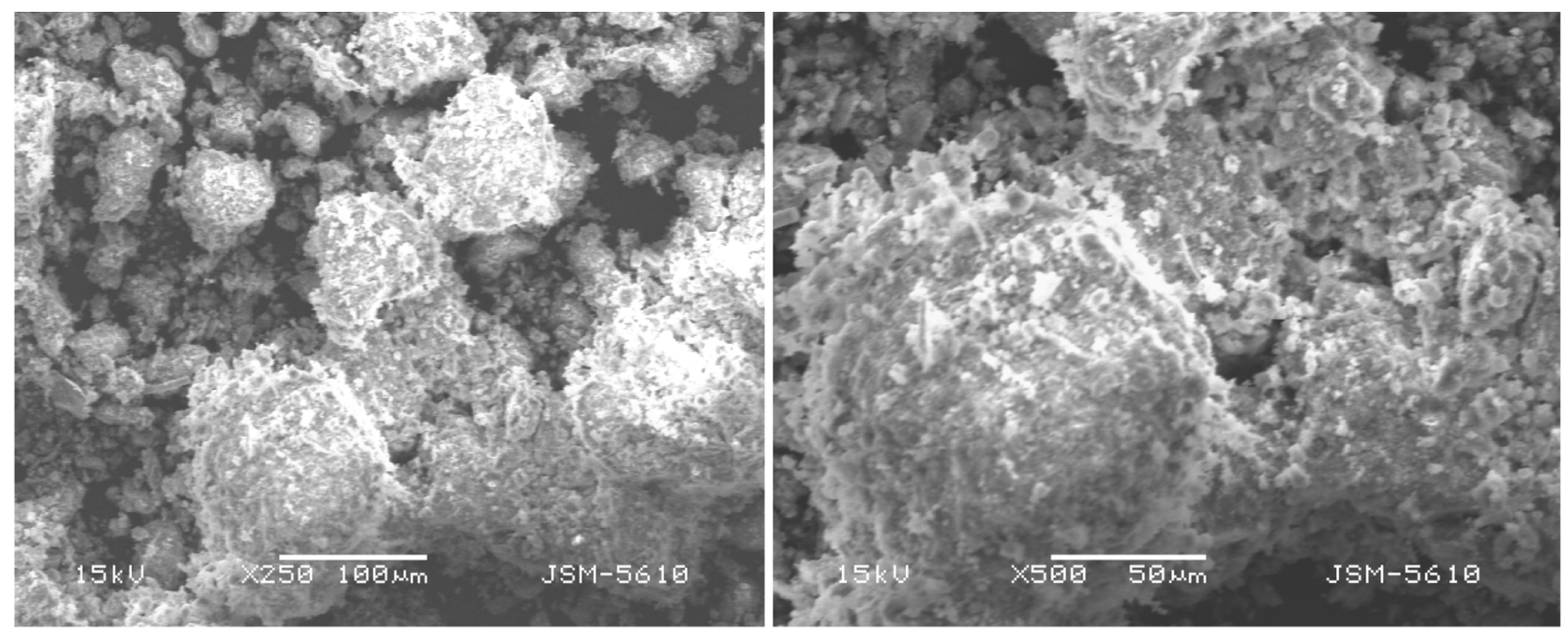

Fig. 1. SEM images of the water treatment sludge. 
$\mathrm{K}$ were also found in the sludge. Scanning electron microscopy (SEM) images (Fig. 1) showed that collected sludge was heterogeneous mixtures of particles with irregular shape and variable sizes with concentration of particle size at around $100 \mu \mathrm{m}$. Amorphous nature of WTS is also evident from Fig. 1. Point zero charge $\left(\mathrm{pH}_{\mathrm{zpc}}\right)$ of the WTS was determined following the procedure of Mehdi et al. [27], and was found to be 6.9.

\subsection{Electroplating Wastewater}

Electroplating wastewater was collected from an industry located at Makarpura, Vadodara, India. Physico-chemical characteristics of the wastewater are given in Table 2. Since the concentration of the metals was very high in the wastewater, it was diluted 100 times with tap water and was used in column studies.

Table 2. Characteristics of the Electroplating Wastewater

\begin{tabular}{lc}
\hline \multicolumn{1}{c}{ Parameter } & Value \\
\hline $\mathrm{pH}$ & 0.66 \\
Electrical conductivity $(\mu \mathrm{S} / \mathrm{cm})$ & 312,800 \\
Total solids $(\mathrm{mg} / \mathrm{L})$ & 69,655 \\
Total dissolved solids $(\mathrm{mg} / \mathrm{L})$ & 68,950 \\
COD (mg/L) & 4,000 \\
Chromium (mg/L) & $3,965.3$ \\
Copper (mg/L) & $1,499.4$ \\
Zinc (mg/L) & 972.3 \\
Mercury (mg/L) & 65.1 \\
Lead (mg/L) & 26.1 \\
Cobalt $(\mathrm{mg} / \mathrm{L})$ & 3.2 \\
\hline
\end{tabular}

\subsection{Batch Sorption Tests}

Batch sorption experiments were conducted at room temperature $\left(23-25^{\circ} \mathrm{C}\right)$ using six different heavy metals namely $\mathrm{Cu}(\mathrm{II}), \mathrm{Co}(\mathrm{II})$, $\mathrm{Cr}(\mathrm{VI}), \mathrm{Hg}(\mathrm{II}), \mathrm{Pb}(\mathrm{II})$ and $\mathrm{Zn}$ (II) employing synthetic metal solutions. Metal solutions with desired concentration were prepared using $\mathrm{Cu}\left(\mathrm{NO}_{3}\right)_{2}, \mathrm{Co}\left(\mathrm{NO}_{3}\right)_{2}, \mathrm{Na}_{2} \mathrm{CrO}_{4}, \mathrm{Hg}(\mathrm{Cl})_{2}, \mathrm{~Pb}\left(\mathrm{NO}_{3}\right)_{2}$, or $\mathrm{ZnSO}_{4}$. Two different types of tests were conducted, one with each metal solution and the other with multi-metal solution where all the six metals were added in equal concentration. In single-metal solution tests, initial metal concentration was kept at $10 \mathrm{mg} / \mathrm{L}$, while in multi-metal solution tests, a total metal concentration of $10 \mathrm{mg} / \mathrm{L}$ with equal concentration for each of the six metals was employed. All the experiments were carried out in $0.01 \mathrm{M} \mathrm{NaNO}_{3}$ solution to maintain equal ionic strength of the solution. The desired amount of sludge was added to $50 \mathrm{~mL}$ solution. Following that, the bottles were shaken in water bath shaker at $150 \mathrm{rpm}$ until equilibrium was achieved. Preliminary kinetic tests were conducted to determine the equilibrium time required for further tests. These tests were conducted with an initial metal concentration of $10 \mathrm{mg} / \mathrm{L}$ and WTS dose of $1 \mathrm{~g} / \mathrm{L}$ at an initial $\mathrm{pH}$ of 5 . This test indicted that a contact time of $2 \mathrm{~h}$ was adequate to reach equilibrium for each of the metals, and subsequently $2 \mathrm{~h}$ contact time was used in all the tests.
In tests to determine the effect of initial $\mathrm{pH}$ on sorption, $\mathrm{pH}$ of the solution was varied in the range of 2.5-8.5, and the $\mathrm{pH}$ was adjusted using $0.1 \mathrm{~N} \mathrm{HCl}$ or $0.1 \mathrm{~N} \mathrm{NaOH}$. For determining effect of sorbent dose on extent of metal removal, tests were conducted at an initial $\mathrm{pH}$ of 5.0 with WTS dosage varying between 0.5 and $10.0 \mathrm{~g} / \mathrm{L}$. After each test, samples were taken out and centrifuged at $6,000 \mathrm{rpm}$ for $5 \mathrm{~min}$ and were analysed for metals.

\subsection{Column Test}

Column tests were conducted at room temperature $\left(23-25^{\circ} \mathrm{C}\right)$ with real electroplating wastewater in a glass column of $2.5 \mathrm{~cm}$ internal diameter and $75 \mathrm{~cm}$ height with WTS medium height of $45 \mathrm{~cm}$ (Fig. 2). The column had a bed volume of $221 \mathrm{~cm}^{3}$ and a pore volume of $83 \mathrm{~cm}^{3}$. The column was operated in upflow mode with a flow rate of $1.2 \mathrm{~mL} / \mathrm{min}$ using a peristaltic pump corresponding to a bed flowthrough time of $3 \mathrm{~h}$. Effluent was collected at regular interval and was analysed for relevant parameters.

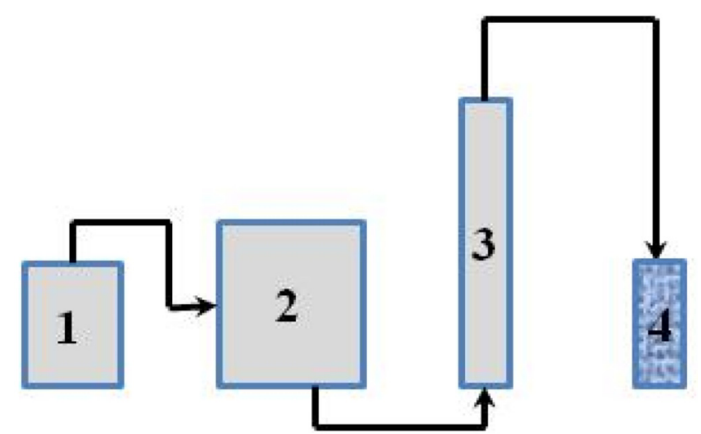

Fig. 2. Continuous flow column set-up (1) wastewater influent, (2) peristaltic pump, (3) WTS column and (4) effluent collection.

\subsection{Analyses}

The solid content of WTS was calculated by the difference in the initial weight of the sludge and dry weight of sludge after being dried in hot air oven at $105^{\circ} \mathrm{C}$ for $24 \mathrm{~h}$ and volatile suspended solids (VSS) of the same was calculated after burning the dry solids in a muffle furnace at $550^{\circ} \mathrm{C}$ for $2 \mathrm{~h}$. Metals were analysed using inductively-coupled plasma atomic emission spectrometry (ICP AEP) (ARCOS Spectro, Germany). The COD of the samples were analysed using the closed reflux titrimetric method in accordance with the Standard Methods [28]. pH was measured using a pH meter (Hanna 209), and electrical conductivity was measured using an electrical conductivity meter (Systronics, India).

\section{Results and Discussion}

\subsection{Kinetic Tests}

It is important that an adsorbent offers rapid sorption to minimise the time required to remove heavy metals, which helps to reduce capital and operational costs. The results of the kinetic tests are presented in Fig. 3. It can be seen that for all the metals tested, there was rapid adsorption initially and it slowed down to reach a constant value. For lead, almost complete sorption occurred 


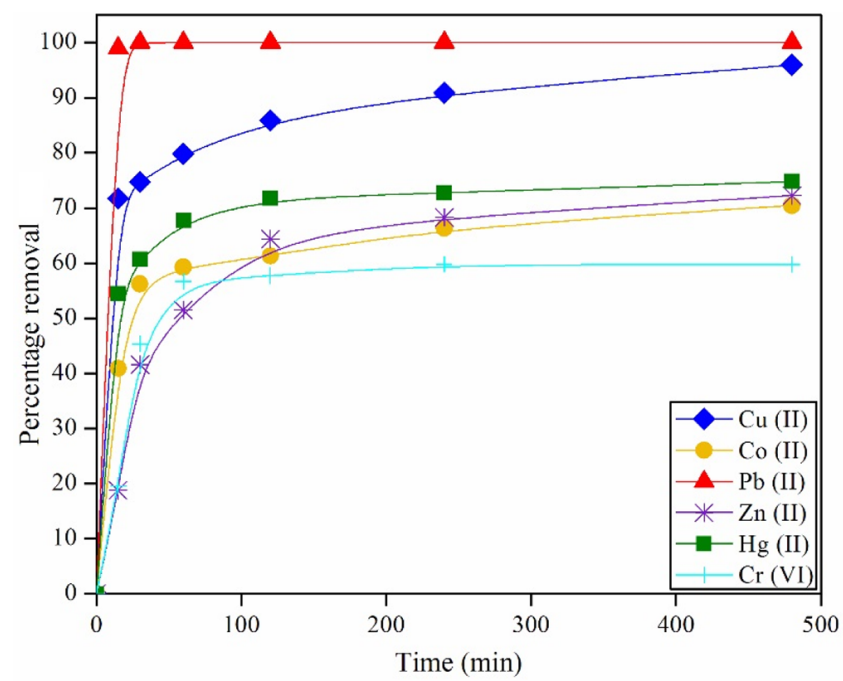

Fig. 3. Effect of contact time on heavy metal removal (initial metal concentration $10 \mathrm{mg} / \mathrm{L}$, sorbent dose $1 \mathrm{~g} / \mathrm{L}$, initial $\mathrm{pH}$ 5.0).

within $15 \mathrm{~min}$. For other metals, no significant increase in removal was observed after $2 \mathrm{~h}$. Thus, an equilibrium time of $2 \mathrm{~h}$ was used in all subsequent tests. It has been reported that $\mathrm{Pb}$ could form strong inner sphere complexes with aluminium and iron oxide surfaces [29]. This could be responsible for complete adsorption of $\mathrm{Pb}$ observed in the present study. Such rapid adsorption by water treatment sludge has been reported for $\mathrm{As}(\mathrm{V})$ by Makris et al. [18].

\subsection{Effect of $\mathrm{pH}$ on Metal Removal}

Effect of initial $\mathrm{pH}$ on metal removal was studied for a $\mathrm{pH}$ range of 2.5-8.5 and the results are presented in Fig. 4(a) and (b), respectively for single metal and multi-metal solutions. It can be observed that for four metals namely, $\mathrm{Cu}(\mathrm{II}), \mathrm{Co}(\mathrm{II}), \mathrm{Hg}(\mathrm{II})$, and $\mathrm{Zn}$ (II) removal increased with increase in initial $\mathrm{pH}$ whereas for $\mathrm{Pb}$ (II) there was no influence of $\mathrm{pH}$, and almost complete removal occurred at all the $\mathrm{pH}$ values tested. $\mathrm{Cr}(\mathrm{VI})$ presented a different trend with higher removal at lower $\mathrm{pH}$ values of 2.5-4.0 and then decreasing with increase in $\mathrm{pH}$.

It is known that the $\mathrm{pH}$ of aqueous solution plays an important role in the adsorption process, affecting the character of both the ions to be removed and the adsorbent itself. In acidic solutions there is a competition between metal cations and the protons present in solution for the adsorption sites. At alkaline $\mathrm{pHs}$ (usually $\mathrm{pH}>7.0$ ), precipitation of metal ions eventually occurs. This $\mathrm{pH}$ value will be different for different metals based on their solubility. This shows that the adsorptive process will occur in a well-defined $\mathrm{pH}$ range [30]. Generally at optimum $\mathrm{pH}$ conditions, the adsorbent and the $\mathrm{pH}$ should have opposite charges for enhanced electrostatic interactions [31].

Further, it is known that the sorption onto an adsorbent is affected by its point of zero charge $\left(\mathrm{pH}_{\mathrm{zpc}}\right)$. The WTS used in the present study had a $\mathrm{pH}_{\mathrm{zpc}}$ of 6.9 , similar to the values reported in the literature [22]. At $\mathrm{pH}$ above this value sludge surface may become negatively charged and hence increased sorption was observed for cationic metals such as $\mathrm{Cu}(\mathrm{II}), \mathrm{Co}(\mathrm{II}), \mathrm{Hg}(\mathrm{II})$, and $\mathrm{Zn}$ (II)
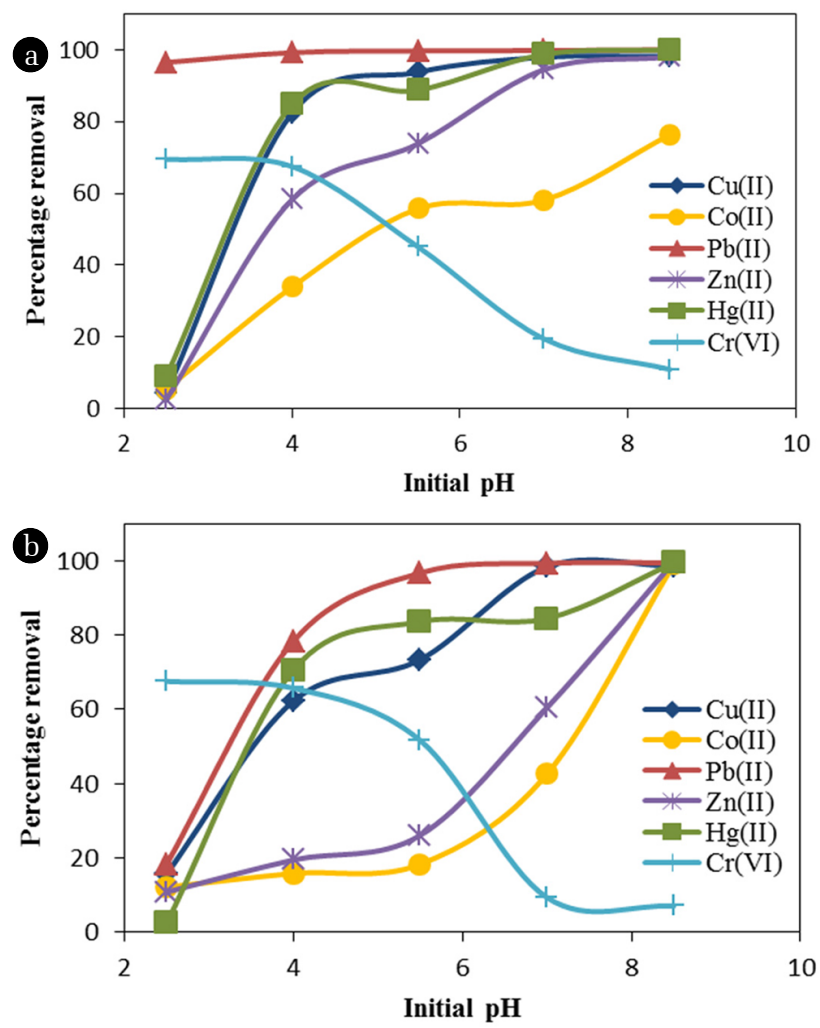

Fig. 4. Effect of $\mathrm{pH}$ on removal of heavy metals in (a) single-metal solution and (b) multi-metal solution (initial metal ion concentration $10 \mathrm{mg} / \mathrm{L}$, WTS dose $1 \mathrm{~g} / \mathrm{L}$, contact time $2 \mathrm{~h}$. In multi-metal solution, total concentration of the six metals was $10 \mathrm{mg} / \mathrm{L}$ ).

at higher $\mathrm{pH}$. It is reported that increase in $\mathrm{pH}$ results in increased formation rate of mixed-cation hydroxide phase [32] and thereby increasing removal at higher $\mathrm{pH}$ values for metal cations. In the case of anionic metals such as $\mathrm{Cr}(\mathrm{VI})$ this will be reversed with higher adsorption at $\mathrm{pH}$ values less than $\mathrm{pH}_{\mathrm{zpc}}$. Similar observations have been reported by Zhou and Haynes [19] and Hovsepyan and Bonzongo [22]. They reported increased removal for cationic metals such as $\mathrm{Pb}$ (II) and $\mathrm{Cr}(\mathrm{III})$ at higher $\mathrm{pH}$ values, while for anionic metal $\mathrm{Cr}(\mathrm{VI})$, removal was reduced at higher $\mathrm{pH}$ values.

Comparison of Fig. 4(a) and (b) shows the effect of competition on metal removal. It can be seen that in the multi-metal system, removal of all the metals except $\mathrm{Cr}(\mathrm{VI})$ were affected at lower initial $\mathrm{pH}$ values. As in the case of single-metal system, metal removal increased with increase in $\mathrm{pH}$ and almost complete removal was observed at $\mathrm{pH} 8.5$ for all the metals except $\mathrm{Cr}(\mathrm{VI})$. It is interesting to note that for Co(II) complete removal was observed at $\mathrm{pH} 8.5$ in multi-metal solution though only about $73 \%$ removal was achieved in single-metal solution. This could be due to co-precipitation of $\mathrm{Co}(\mathrm{II})$ along with other metals at higher $\mathrm{pH}$ values. In the case of $\mathrm{Cr}(\mathrm{VI})$, removal was unaffected in the $\mathrm{pH}$ range studied. $\mathrm{Cr}(\mathrm{VI})$ is an anionic metal, and lower removal of other metals at lower $\mathrm{pH}$ values did not pose competition for $\mathrm{Cr}(\mathrm{VI})$ at these pHs. It may also be noted that sorption of Co(II) and $\mathrm{Zn}$ (II) was more impacted compared to other metals in the multi-metal system. 
It may be noted that initial $\mathrm{pH}$ of the metal solution was adjusted to the desired values before addition of WTS and no adjustment was done during the sorption process. It was observed that after the contact time of $2 \mathrm{~h}$, the final $\mathrm{pH}$ of the reaction mixture was increased in the range of $0.10-1.10$, with higher increase for solutions with lower initial $\mathrm{pH}$ values. It is also interesting to note that the total amount of metals removed in multi-metal system was less compared to the removal in the single-metal solution in the $\mathrm{pH}$ range of 2.5-7.0. However, at the highest test $\mathrm{pH}$ of 8.5, the total metal removal was significantly higher in the multi-metal system possibly due to co-precipitation.

\subsection{Effect of WTS Dose on Metal Removal}

The effect of WTS dose on metal sorption was studied in the range of 0.5-10.0 g/L for both single metal and multi-metal systems, and the results are presented in Fig. 5(a) and (b), respectively. It is clear from Fig. 5(a) that in the case of single metal system, there was no impact of WTS dose on the removal of $\mathrm{Pb}(\mathrm{II})$ and $\mathrm{Cu}(\mathrm{II})$, with $\mathrm{Pb}(\mathrm{II})$ showing almost complete removal at all the doses. $\mathrm{Cu}(\mathrm{II})$ removal remained in a narrow range of $89-94 \%$ for different doses of WTS. For $\mathrm{Hg}(\mathrm{II})$ and $\mathrm{Zn}$ (II), percentage removal
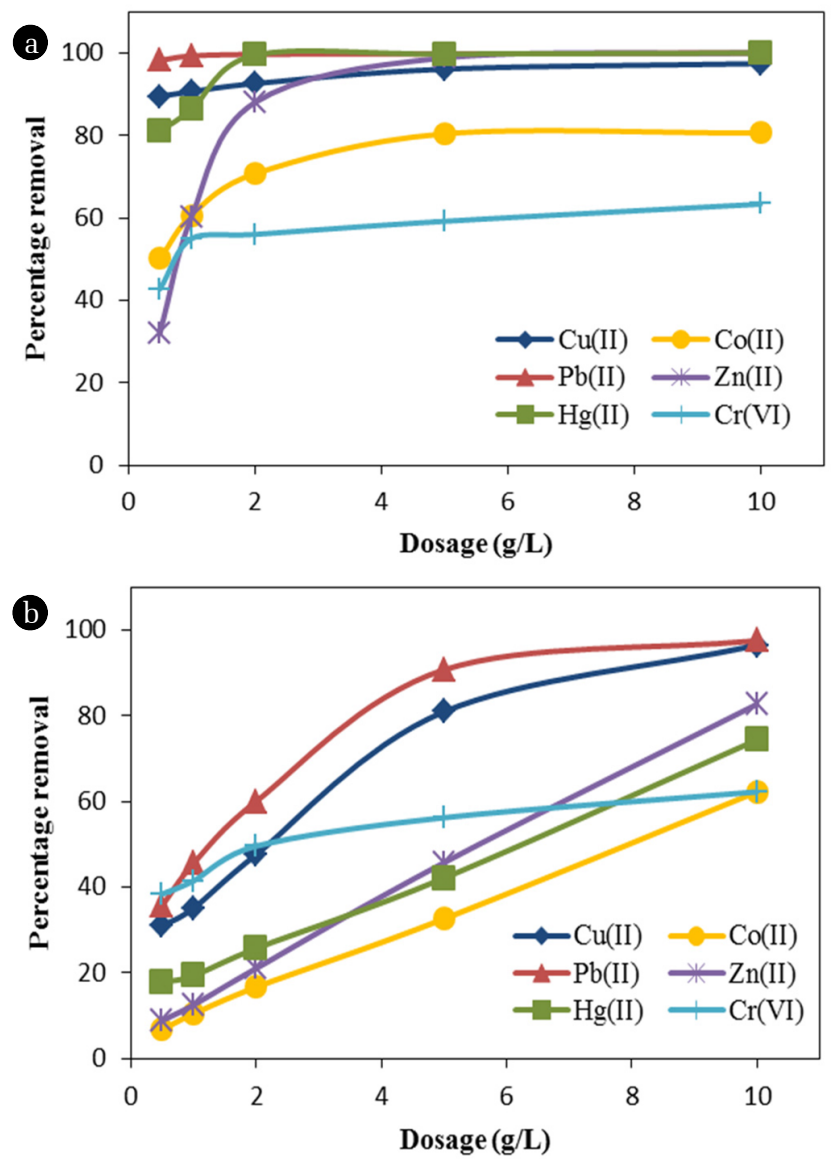

Fig. 5. Effect of WTS dose on removal of heavy metals in (a) single-metal solution and (b) multi-metal solution (initial metal ion concentration $10 \mathrm{mg} / \mathrm{L}, \mathrm{pH}$ 5.0, contact time $2 \mathrm{~h}$. In multi-metal solution, total concentration of the six metals was $10 \mathrm{mg} / \mathrm{L}$ ). increased with WTS dose and removal in excess of 97\% were observed at the highest dose of $10 \mathrm{~g} / \mathrm{L}$. For Co(II), however, the removal remained below $80 \%$ even at the highest WTS dose. Cr(VI) removal did not improve significantly beyond a dose of $1 \mathrm{~g} / \mathrm{L}$ and remained below $60 \%$ at higher doses.

The effect of competition on metal removal can be observed by comparing Fig. 5(a) and (b). Similar to the results of the tests on effect of $\mathrm{pH}$, this test also showed reduced removal of different metals in the multi-metal system. The effect was, however, highly significant at lower WTS doses. At the highest WTS dose of 10 $\mathrm{g} / \mathrm{L}$, removal of $\mathrm{Cu}(\mathrm{II})$ and $\mathrm{Pb}(\mathrm{II})$ were almost similar to the those in single metal system showing preferential adsorption for these metals compared to others. Cr(VI) was least affected by competition as its removal was similar to that in single metal solution. Availability of larger number of sorption sites at higher WTS doses reduced the influence of competition in multi-metal system, thereby increasing the metal removal.

\subsection{Column Test}

Results of the column test conducted with real electroplating wastewater are presented in Fig. 6 and Fig. 7. It can be observed from Fig. 6 that complete removal of copper occurred up to about 100 bed volumes and a sudden reduction in its removal was found after that. Chromium removal was also high (78-92\%) during the column operation. The effluent $\mathrm{Cr}(\mathrm{VI})$ concentration was still high (3-8 $\mathrm{mg} / \mathrm{L}$ ) due to its high influent concentration. It is evident that the removal of copper was not affected by the presence of chromium as complete removal was observed for 100 bed volumes. Further, while batch studies showed only up to a maximum of about $40 \%$ $\mathrm{Cr}(\mathrm{VI})$ removal at an initial $\mathrm{pH}$ of 6.0 , column tests showed much higher $\mathrm{Cr}(\mathrm{VI})$ removal showing the effectiveness of WTS in adsorbing metals in column operation. Also, other heavy metals present in the wastewater, though at low concentration, namely $\mathrm{Zn}$ (II), $\mathrm{Hg}$ (II) and $\mathrm{Pb}$ (II), were also removed effectively during the column operation and their concentrations were below $0.05 \mathrm{mg} / \mathrm{L}$ in the effluent throughout the column operation of 110 bed volumes.

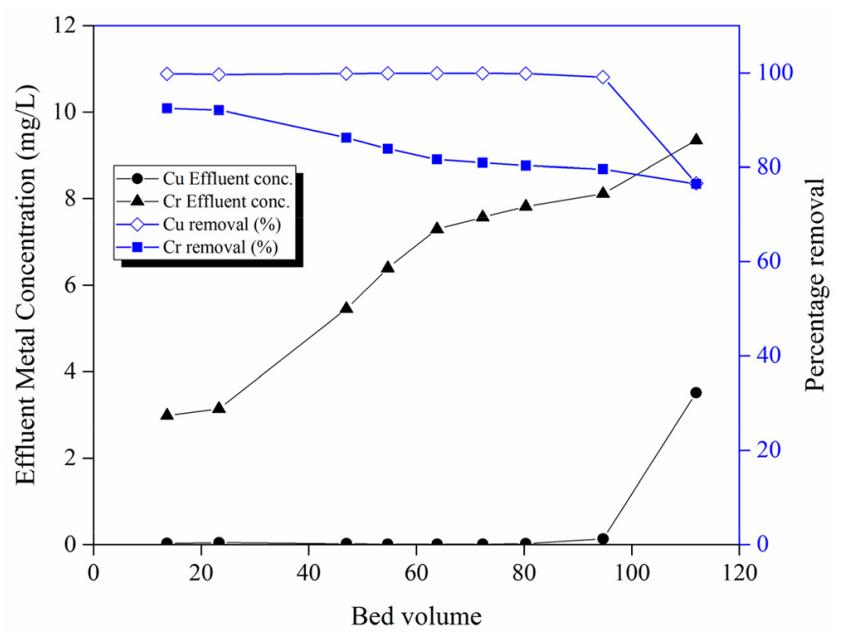

Fig. 6. Heavy metal removal in column test (Bed flow through time $3 \mathrm{~h}$, flowrate $1.2 \mathrm{~mL} / \mathrm{min}$, column height $45 \mathrm{~cm}$, influent $\mathrm{pH}$ 6.0, influent $\mathrm{Cr}(\mathrm{VI}) 39.653 \mathrm{mg} / \mathrm{L}$, influent $\mathrm{Cu}(\mathrm{II}) 14.994 \mathrm{mg} / \mathrm{L})$. 


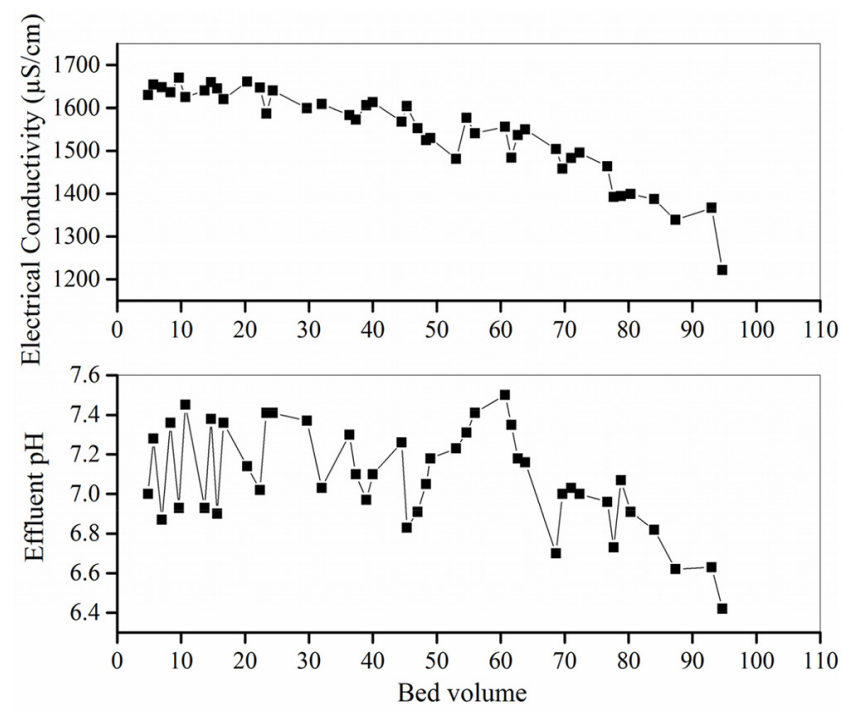

Fig. 7. Variation in $\mathrm{pH}$ and electrical conductivity in the effluent with bed volume (Influent pH 6.0, influent electrical conductivity 3,230 $\mu \mathrm{S} / \mathrm{cm})$.

Effluent $\mathrm{pH}$ and electrical conductivity were also monitored during the column test, and are shown in Fig. 7. While the $\mathrm{pH}$ of the original wastewater was 0.66 , the diluted wastewater had an initial $\mathrm{pH}$ of 6.0. Passage of wastewater through the WTS column resulted in an increase in $\mathrm{pH}$ and the effluent $\mathrm{pH}$ varied in the range of 6.5-7.5. This shows that WTS column can act as a buffering system for low-pH heavy metal-laden wastewater bringing the effluent $\mathrm{pH}$ to neutral values. Initial conductivity of the influent was $3,230 \mu \mathrm{S} / \mathrm{cm}$ and effluent conductivity showed a decreasing trend throughout the operation with its removal varying in the range of $49-63 \%$.

Mass balance for copper and chromium for the system based on the metal removal for 110 bed volumes showed that the WTS medium had a $\mathrm{Cu}(\mathrm{II})$ and $\mathrm{Cr}(\mathrm{VI})$ sorption capacities of about 1.7 and $3.5 \mathrm{mg} / \mathrm{g}$ of dried sludge, respectively. In addition, the media also removed substantial quantities of $\mathrm{Zn}$ (II) and $\mathrm{Hg}$ (II). The $\mathrm{Cu}$ (II) and $\mathrm{Cr}(\mathrm{VI})$ sorption capacities of WTS reported in the literature are generally higher. For example, Lee et al. [33] and Zhou and Haynes [19] reported 3.94 and $11.4 \mathrm{mg} / \mathrm{g}$ for $\mathrm{Cu}(\mathrm{II})$ and $\mathrm{Cr}(\mathrm{VI})$, respectively. However, these values were based on adsorption isotherms obtained from batch tests with single metal synthetic solutions. Further, characteristics of WTS such as aluminium and iron contents in the sludge also influence the adsorption capacity. Also, in the present study, the sorption capacity was estimated based on 110 bed volumes and the medium was not exhausted completely.

The column effluent was also monitored for COD and the values were less than $20 \mathrm{mg} / \mathrm{L}$ throughout the operation, thus ruling out the possibility of leaching of organic matter during the column operation. Column effluent was also monitored for aluminium and iron leaching from WTS. Aluminium and iron concentrations were found to be in the range $0.09-0.13 \mathrm{mg} / \mathrm{L}$ and $0.4-0.9 \mathrm{mg} / \mathrm{L}$, respectively, thus ruling out the possibility of metal leaching from WTS.
Chemical coagulation and precipitation with aluminium or iron salts are the most common methods used for treating heavy metal-rich wastewaters in developing countries like India. However, these techniques generate large quantity of toxic waste, disposal of which poses a problem. Further, precipitation method cannot produce an effluent with low metal concentrations conforming to the discharge standards. Water treatment sludge, a waste product available in large quantities, can be used to treat this type of wastewater. As shown in this study, column operation with WTS medium can produce very low metal concentration in the effluent from a real wastewater containing different metals, thus indicating the potential of WTS for handling metal-rich wastewaters.

While these tests showed the potential of aluminium-based water treatment sludge as a filtration/adsorption medium for heavy metal removal, more studies should be conducted to understand the mechanism of the removal and release of sorbed metals from the medium. Recent studies by Castaldi et al. [23] showed that larger part of the removed metals on WTS were tightly bound to the medium and would not be readily released under normal environmental conditions, while a smaller fraction was in water-soluble and exchangeable form.

\section{Conclusions}

The potential of aluminium-based WTS for heavy metal removal from simulated and real electroplating wastewater was assessed using batch and long-term column tests. Batch tests with simulated wastewater containing $\mathrm{Cu}$ (II), $\mathrm{Co}(\mathrm{II}), \mathrm{Cr}(\mathrm{VI}), \mathrm{Hg}(\mathrm{II}), \mathrm{Pb}(\mathrm{II})$ and $\mathrm{Zn}$ (II) showed the influence of initial $\mathrm{pH}$ on metal removal by WTS in single- and multi-metal solutions. While removal of cationic metals such as $\mathrm{Pb}(\mathrm{II}), \mathrm{Cu}(\mathrm{II})$ and $\mathrm{Zn}$ (II) increased with increase in $\mathrm{pH}$, anionic $\mathrm{Cr}(\mathrm{VI})$ showed a reduction in removal with increase in $\mathrm{pH}$ values. Complete removal of $\mathrm{Pb}(\mathrm{II})$ was obtained at all the $\mathrm{pH}$ values tested, even with low WTS doses. Tests with different doses of WTS showed reduced removals of different metals in the multi-metal system compared to single metal solution. This effect was, however, more pronounced at lower WTS doses. Column test with real electroplating wastewater showed complete removal of copper, zinc and mercury up to 100 bed volumes while chromium removal ranged between $78-92 \%$. No leaching of organic matter present in the WTS was observed during the column operation. WTS showed $\mathrm{Cu}(\mathrm{II})$ and $\mathrm{Cr}(\mathrm{VI})$ adsorption capacities of about 1.7 and $3.5 \mathrm{mg} / \mathrm{g}$ of dried sludge, respectively. This study thus indicates that water treatment sludge can be a good sorption medium for metals in metal-bearing wastewaters.

\section{References}

1. Matis KA, Zouboulis AI, Gallios GP, Erwe T, Blocher C. Application of flotation for the separation of metal-loaded zeolites. Chemosphere 2004;55:65-72.

2. Teh CY, Budiman PM, Shak KPY, Wu TY. Recent advancement of coagulation-flocculation and its application in wastewater treatment. Ind. Eng. Chem. Res. 2016;55:4363-4389.

3. Ghosh A, Dastidar MG, Sreekrishnan TR. Recent advances 
in bioremediation of heavy metals and metal complex dyes: Review. J. Environ. Eng. 2016;142:1-14.

4. Natarajan R, Manivasagan R. Biosorptive removal of heavy metal onto raw activated sludge: Parametric, equilibrium, and kinetic studies. J. Environ. Eng. 2016;142:1-6.

5. Febrianto J, Kosasih AN, Sunarso J, Ju YH, Indraswati N, Ismadji S. Equilibrium and kinetic studies in adsorption of heavy metals using biosorbent: A summary of recent studies. J. Hazard. Mater. 2008;162:616-645.

6. Fu F, Wang Q. Removal of heavy metal ions from wastewaters: A review. J. Environ. Manage. 2011;92:407-418.

7. Teh CY, Wu TY. The potential use of natural coagulants and flocculants in the treatment of urban waters. Chem. Eng. Trans. 2014;39:1603-1608.

8. Makris KC, Sarkar D, Parsons JG, Datta R. X-ray absorption spectroscopy as a tool investigating arsenic(III) and arsenic(V) sorption by an aluminium-based drinking-water treatment residual. J. Hazard. Mater. 2009;171:980-986.

9. Babatunde AO, Zhao YQ. Constructive approaches toward water treatment works sludge management: An international review of beneficial re-uses. Crit. Rev. Environ. Sci. Technol. 2007;37:129-164.

10. Ippolito JA, Scheckel KG, Barbarick KA. Selenium adsorption to aluminum-based water treatment residuals. J. Colloid Interface Sci. 2009;338:48-55.

11. Makris KC, O’Connor GA. Beneficial utilization of drinking-water treatment residuals as contaminant-mitigating agents. In: Sarkar D, Datta R, Hannigan R, eds. Developments in environmental science, concepts and applications in environmental geochemistry, vol. 5. Amsterdam: Elsevier Sciences; 2007. p. 607-636.

12. Ahmad T, Ahmad K, Alam M. Sustainable management of water treatment sludge through 3'R' concept. J. Clean. Prod. 2016;124:1-10.

13. Shak KPY, Wu TY. Optimized use of alum together with unmodified Cassia obtusifolia seed gum as a coagulant aid in treatment of palm oil mill effluent under natural $\mathrm{pH}$ of wastewater. Ind. Crops Prod. 2015;76:1169-1178.

14. Muisa N, Hoko Z, Chifamba P. Impacts of alum residues from Morton Jaffray Water Works on water quality and fish, Harare, Zimbabwe. Phys. Chem. Earth 2011;36:853-864.

15. Nair AT, Ahammed MM. Coagulant recovery from water treatment plant sludge and reuse in post-treatment of UASB reactor effluent treating municipal wastewater. Environ. Sci. Pollut. Res. 2014;21:10407-10418.

16. Makris KC, Harris WG, O’Connor GA, Obreza TA. Phosphorus immobilization in micropores of drinkingwater treatment residuals: Implications for long-term stability. Environ. Sci. Technol. 2004;38:6590-6596.

17. Gibbons MK, Gagnon GA. Adsorption of arsenic from a Nova
Scotia groundwater onto water treatment residual solids. Water Res. 2010;44:5740-5749.

18. Makris KC, Sarkar D, Datta R. Evaluating a drinking-water waste by-product as a novel sorbent for arsenic. Chemosphere 2006;64:730-741.

19. Zhou YF, Haynes RJ. Removal of $\mathrm{Pb}(\mathrm{II}), \mathrm{Cr}(\mathrm{III})$ and $\mathrm{Cr}(\mathrm{VI})$ from aqueous solutions using alum-derived water treatment sludge. Water Air Soil Pollut. 2011;215:631-643.

20. Putra RS, Tanaka S. Aluminum drinking water treatment residuals (Al-WTRs) as an entrapping zone for lead in soil by electrokinetic remediation. Sep. Purif. Technol. 2011;79:208-215.

21. Irawan C, Liu JC, Wu C. Removal of boron using aluminum-based water treatment residuals (Al-WTRs). Desalination 2011;276:322-327.

22. Hovsepyan A, Bonzongo JJ. Aluminum drinking water treatment residuals (Al-WTRs) as sorbent for mercury: Implications for soil remediation. J. Hazard. Mater. 2009;164:73-80.

23. Castaldi P, Silvetti M, Garau G, Demurtas D, Deiana S. Copper(II) and lead(II) removal from aqueous solution by water treatment residues. J. Hazard. Mater. 2015;283:140-147.

24. Caporale AG, Punamiya P, Pigna M, Violante A, Sarkar D. Effect of particle size of drinking-water treatment residuals on the sorption of arsenic in the presence of competing ions. J. Hazard. Mater. 2013;260:644-651.

25. Ippolito JA, Barbarick KA, Elliott HA. Drinking water treatment residuals: A review of recent uses. J. Environ. Qual. 2011;40:1-12.

26. USEPA. Method 3050B: Acid digestion of sediment, sludge and soils. 2nd ed. US Environmental Protection Agency, Washington D.C., USA; 1996.

27. Mehdi SS, Khataee A, Joo SW. Kinetics and equilibrium studies on removal of an azo dye from aqueous solution by adsorption onto scallop. Ind. Eng. Chem. 2014;20:610-618.

28. Standard methods for the examination of water and wastewater. 20th ed. In: Clescerl LS, Greenberg AE, Eaton AD, eds. American Public Health Association/American Water Works Association/ Water Environment Federation, Washington D.C., USA; 1998.

29. Sparks DL. Environmental soil chemistry. 2nd ed. Amsterdam, The Netherlands: Academic Press; 2003.

30. Yang W, Tang Q, Wei J, Ran Y, Chai L, Wang H. Enhanced removal of $\mathrm{Cd}(\mathrm{II})$ and $\mathrm{Pb}(\mathrm{II})$ by composites of mesoporouscarbon stabilized alumina. Appl. Surf. Sci. 2016;369:215-223.

31. Çoruh S, Şenel G, Ergun ON. A comparison of the properties of natural clinoptilolites and their ion-exchange capacities for silver removal. J. Hazard. Mater. 2010;180:486-492.

32. Elzinga EJ, Sparks DL. Reaction condition effects on nickel sorption mechanisms in illite-water suspensions. Soil Sci. Soc. Am. J. 2001;65:94-101.

33. Lee CI, Yang WF, Chiou CS. Utilization of water clarifier sludge for copper removal in a liquid fluidized-bed reactor. J. Hazard. Mater. 2006;129:58-63. 